
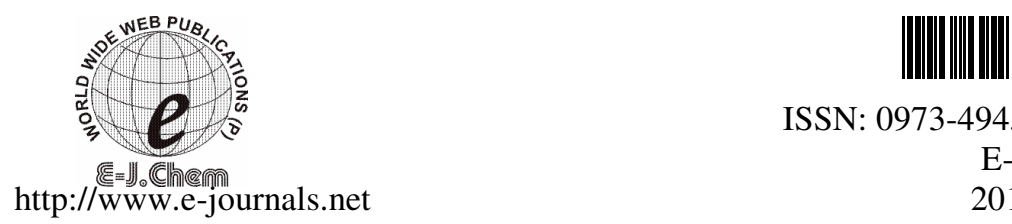

ISSN: 0973-4945; CODEN ECJHAO

E-Journal of Chemistry

2010, 7(S1), S386-S390

\title{
HPLC Method Development and Validation for Simultaneous Analysis of Diclofenac Sodium and Rabeprazole Sodium
}

\author{
A.A HEDA*, D D. GADADE, J M. KATHIRIYA and P K. PURANIK \\ Department of Pharmaceutics, Government College of Pharmacy \\ Vedant Road, Osmanpura, Auragabad-431005, India \\ aaheda@rediffmail.com
}

Received 3 March 2010; Accepted 1 May 2010

\begin{abstract}
A stable, simple, rapid, precise, accurate RP-HPLC method for simultaneous analysis of diclofenac sodium and rabeprazole sodium was developed and validated as per ICH guidelines without need of any internal standard. Separation was carried out using C8 column with triethyl amine buffer (pH 5): acetonitrile (50:50 v/v) as mobile phase with flow rate $2 \mathrm{~mL} \mathrm{~min}^{-1}$. The detection was carried out at $284 \mathrm{~nm}$. The parameters studied were retention time, linearity and range, accuracy, precision, detection limit, quantitation limit and bench top stability. The proposed method can be used for simultaneous estimation of diclofenac sodium and rabeprazole sodium in bulk drugs and pharmaceutical dosage forms.
\end{abstract}

Keywords: Diclofenac sodium, Rabeprazole sodium, RP-HPLC, Validation.

\section{Introduction}

Diclofenac sodium $\{2-[(2,6-$ Dichlorophenyl $)$ amino $]$ benzene acetic acid sodium salt $\}$ (DICLO) is a phenyl acetic derivative used as non-steroidal anti-inflammatory agent. Rabeprazole sodium \{2-[[[4-(3-methoxypropoxy)-3- methyl-2 pyridinyl] methyl] sulfinyl]$1 H$-benzimidazole sodium salt $\}(\mathrm{RAB})$, a benzimidazole derivative a proton pump inhibitor (PPI) used as acid suppressing agent. Several UV spectrophotometric, voltametric or HPLC methods are reported for DICLO and RAB as individual component or with other drugs ${ }^{1-8}$. Reported simultaneous determination method for DICLO and RAB requires indapamide as an internal standard and using methanol as a solvent ${ }^{9}$. In present study the simple, rapid, precise, accurate, sensitive and stable RP-HPLC method has been developed without use of any internal standard as per ICH guidelines ${ }^{10}$. Alkaline borate buffer of $\mathrm{pH} 8$ was utilized as 
a solvent which can be used as dissolution medium for dissolution study of the DICLO and $\mathrm{RAB}$ in combined formulation. However $0.5 \mathrm{M}$ sodium hydroxide was used for the stabilization of RAB. The method was developed for simultaneous estimation of DICLO and $\mathrm{RAB}$ in the pharmaceutical formulations.

\section{Experimental}

The chromatographic separation and simultaneous analysis of DICLO and RAB was carried out using Dionex chromatographic system (Germering, Germany) equipped with Automated sample injector (P680) plus HPLC pump (ASI 1000) plus UV detector (UVD170U), Rheodyne injector and Chromeleon ${ }^{\circledR}$ acquision software Ver.6.70. BDS Hypersil C8 column ( $250 \mathrm{~mm}$ x.4.6 $\mathrm{mm}, 5 \mu$ ) was used for the separation. The $0.22 \mu \mathrm{m}$ nylon filters (Millipore) and Vacuum pump (Rocker pump 400 Today's) were used for filtration while ultrasonication was carried out with ultrsonicator (USR 100 Spectralab).

Diclofenac sodium (Glenmark Ltd., Nasik), rabeprazole sodium (Wockhardts Ltd., Aurangabad), triethyl amine (Merck Ltd., Mumbai), acetonitrile (Qualigens), boric acid (Qualigens), potassium chloride (Loba chem), orthophosphoric acid (Qualigens) and sodium hydroxide (Merck Ltd., Mumbai), etc. were used in this work.

\section{Genaral procedure}

The chromatographic parameters were as given in Table 1.

Table 1. Chromatographic conditions

\begin{tabular}{|c|c|}
\hline Mobile Phase & $\begin{array}{l}\text { Acetonitrile (ACN): aqueous triethyl amine } \\
\text { (TEA) buffer }(50: 50 \mathrm{v} / \mathrm{v})\end{array}$ \\
\hline $\mathrm{pH}$ & 5.00 (adjusted with phosphoric acid) \\
\hline Flow rate & $2 \mathrm{~mL} \mathrm{~min}^{-1}$ \\
\hline Injection volume & $10 \mu \mathrm{L}$ \\
\hline Elusion type & Isocratic elusion \\
\hline Detection wavelength & $284 \mathrm{~nm}$ \\
\hline Column & BDS Hypersil C8 $(250 \mathrm{~mm} \times 4.5 \mathrm{~mm}, 5 \mu \mathrm{m})$ \\
\hline Temperature & $25 \pm 2{ }^{\circ} \mathrm{C}$ \\
\hline
\end{tabular}

\section{Preparation of standard stock solutions}

Standard stock solutions of DICLO and RAB, $10 \mathrm{mg} / \mathrm{dL}$ were prepared in $\mathrm{pH} 8$ alkaline borate buffer I.P. The standard solutions of DICLO and RAB in mixture were prepared from standard stock solution using $\mathrm{pH} 8$ alkaline borate buffer I.P with one $\mathrm{ml}$ addition of $0.5 \mathrm{M}$ sodium hydroxide to each solution in calibrated volumetric flask of capacity $5 \mathrm{~mL}$. The prepared standard solutions of DICLO and RAB were ranging from $25-125 \mu \mathrm{g} \mathrm{mL}^{-1}$ and $5-25 \mu \mathrm{g} \mathrm{mL}^{-1}$ respectively. The representative chromatogram is shown in Figure 1. Use of non-actinic glass vials and incorporation of sodium hydroxide in standard solutions found to decrease degradation of RAB.

\section{Preparation of calibration curve}

An aliquot of $10 \mu \mathrm{L}$ of each standard solution was injected and chromatogram recorded for each solution. The calibration curves were obtained by plotting peak area versus concentration. All peaks were integrated by using software Chromeleon ${ }^{\circledR}$. The equations of regression lines obtained are as follows:

For RAB: $y=0.1594 x+0.2458\left(r^{2}=0.9987\right)$, For DICLO: $y=0.1925 x-0.0546\left(r^{2}=0.9985\right)$. 


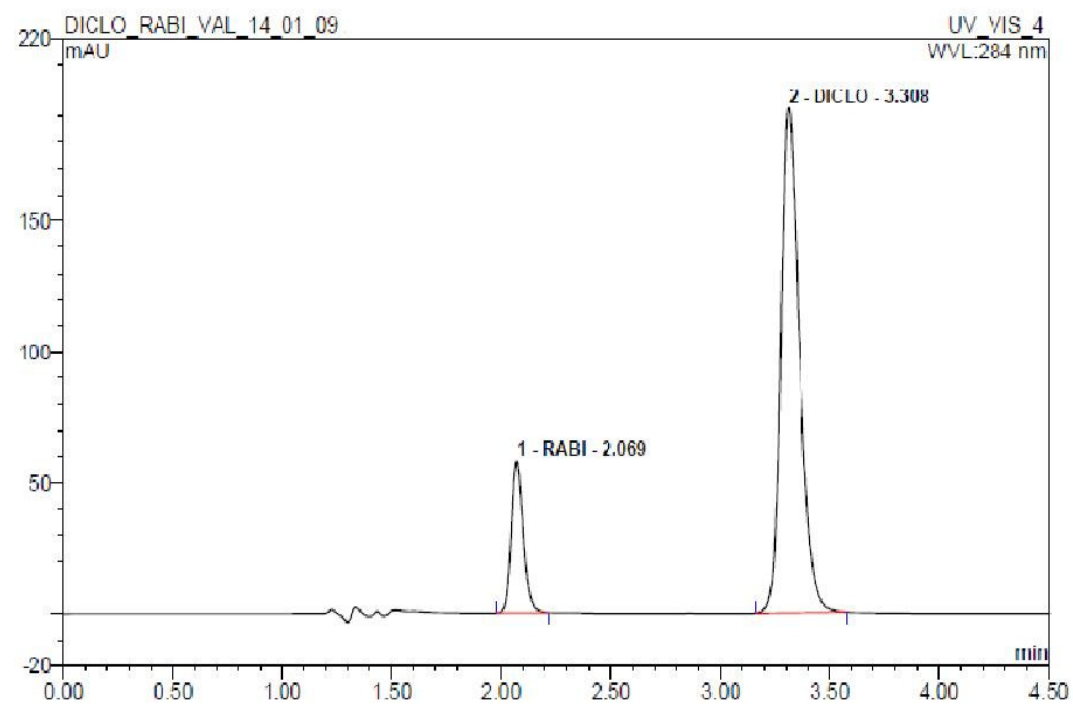

Figure 1. Representative chromatogram of DIClO and RAB

\section{Procedure for assay of marketed formulation}

Twenty capsules (Trade Name: Safediclo, Emcure, Ltd. Pune) procured from market were weighed by individually emptying the contents of capsules. The granules were powdered and powder equivalent to average weight of granules from 20 capsules were added to $100 \mathrm{~mL}$ calibrated volumetric flask wrapped with aluminum foil. The $20 \mathrm{~mL}$ of $0.5 \mathrm{M} \mathrm{NaOH}$ solution was immediately added to the flask with further addition of 30 $\mathrm{mL}$ ice cold $\mathrm{pH} 8$ alkaline borate buffers. The contents of flask were sonicated by keeping flask in ice cold bath for $10 \mathrm{~min}$. Then flask was again cooled and volume was made up to $100 \mathrm{~mL}$ with $\mathrm{pH} 8$ alkaline borate buffer. The solution was transferred to centrifuge tubes and centrifuged at $3500 \mathrm{rpm}$ for $5 \mathrm{~min}$, supernatant was collected and filtered through $0.22 \mu \mathrm{m}$ nylon filter (Millipore) using a syringe filter (Tarsons) mounted on the Luer Lok syringe (Becton Dickinson). The one $\mathrm{mL}$ of filtrate was diluted to ten $\mathrm{mL}$ in calibrated volumetric flask with $\mathrm{pH} 8$ alkaline borate buffer and $10 \mu \mathrm{L}$ was injected in triplicate to column. The concentration of DICLO and RAB in the formulation was calculated by comparing with standard calibration curve.

\section{Validation of RP-HPLC method}

The HPLC method was validated based on ICH guidelines with validation parameters viz. linearity and range, accuracy, precision, limit of detection and limit of quantitation. The bench top stability and system suitability studies were also performed.

\section{Linearity and range}

The linearity of the method was determined at five concentration levels ranging from 25-125 $\mu \mathrm{g} \mathrm{mL}{ }^{-1}$ for DILCO and 5-25 $\mu \mathrm{g} \mathrm{mL}^{-1}$ for RAB.

\section{Accuracy}

The accuracy of method was determined using three concentrations in triplicate at ratios 75:15,100:20 and 125:25 $\mu \mathrm{g} \mathrm{mL}^{-1}$ for DILCO: RAB. The percent recovery within $98-100 \%$ illustrates accuracy of the method. 


\section{Precision}

The method is validated using six determinations at $100 \%$ of test concentrations for repeatability and three concentrations at 3 levels for intermediate precision. The RSD not more than 2 indicates precise method.

\section{Limit of detection (LOD) and limit of quantitation (LOQ)}

The limit of detection and limit of quantitation were calculated from the standard deviation approach.

\section{Bench top stability study}

The standard solution containing $100 \mu \mathrm{g} \mathrm{mL} L^{-1}$ and $20 \mu \mathrm{g} \mathrm{mL}^{-1}$, DICLO and RAB respectively were kept at room temperature for $24 \mathrm{~h}$ and then samples were analyzed.

\section{System suitability}

The asymmetry factor not more than 2 , relative standard deviation of peak areas of six replicate injections not more than 2 and resolution of peaks of DILCO and RAB not less than 2 and theoretical plates not less than 2000 qualifies the system suitability.

\section{Results and Discussion}

The RP-HPLC method was developed for DICLO and RAB with sharp and well resolved peaks. The use of $0.5 \mathrm{M} \mathrm{NaOH}$ and non-actinic glassware found to improve stability of RAB in solution. The different mobile phases at various $\mathrm{pH}$ and different flow rates were examined and mobile phase with ACN: TEA (50:50) pH 5.00 was selected as optimal mobile phase based on system suitability parameters with well resolved peaks of DICLO and RAB.

The wavelength for the detection of both compounds was $284 \mathrm{~nm}$ with best detector response. The method was found to be linear at range of $25-125 \mu \mathrm{g} \mathrm{mL} \mathrm{m}^{-1}$ for DICLO and $5-25 \mu \mathrm{g} \mathrm{mL}^{-1}$ for RAB. The developed method was found to be accurate, precise and quite stable with acceptable values of LOD and LOQ. Validation and other parameters are reported in Table 2.

Table 2. Validation parameters

\begin{tabular}{|c|c|c|}
\hline Parameters & RAB & DICLO \\
\hline Retention time & $2.06 \mathrm{~min}$ & $3.30 \mathrm{~min}$ \\
\hline Wavelength, nm & 284 & 284 \\
\hline No. of data points & 5 & 5 \\
\hline Range, $\mathrm{mg} \mathrm{lit}^{-1}$ & $5-25$ & $25-125$ \\
\hline Regration coefficient & 0.9987 & 0.9985 \\
\hline Slope & 0.1594 & 0.1924 \\
\hline Intercept & 0.2458 & -0.05464 \\
\hline Accuracy, \% & $99.3073 \pm 1.0323$ & $99.7556 \pm 0.2127$ \\
\hline Intraday Precision & 0.2401 & 0.0156 \\
\hline Interday Precision & 0.4494 & 0.3649 \\
\hline Repeatability & 0.5279 & 0.3649 \\
\hline Assay, \% & $99.5857 \pm 0.4649$ & $100.0776 \pm 0.2510$ \\
\hline $\mathrm{LOD} \mu \mathrm{g} \mathrm{mL}^{-1}$. & 0.00824 & 0.07342 \\
\hline $\mathrm{LOQ} \mu \mathrm{g} \mathrm{mL}^{-1}$ & 0.02508 & 0.22248 \\
\hline Bench top recovery, \% & $97.4253 \pm 0.4267$ & $99.7251 \pm 0.1014$ \\
\hline No. of Theoretical Plates & 7483 & 7567 \\
\hline
\end{tabular}




\section{Conclusion}

The RP-HPLC method developed for simultaneous analysis of DICLO and RAB can be used for routine quality control of their bulk drug mixture and their combined dosage form.

\section{Acknowledgments}

The authors thanks to M/s. Glenmark Ltd, Nasik and M/s. Wockhardts Ltd., Aurangabad for providing gift samples of diclofenac sodium and rabeprazole sodium respectively. The authors are also thankful to Dr. V. K. Mourya, Principal, Government College of Pharmacy, Aurangabad for providing necessary facilities to carry out the research work.

\section{References}

1. Mitic S, Miletic G, Pavloc A, Tosic S and Pecev E, Chem Pharm Bull., 2007, 55, 1423.

2. Arcelloni C, Lanzi R, Pedercini S, Molteni G, Fermo I, Pontiroli A and Paroni R, $J$ Chromatogr B., 2001, 763(1-2), 195-200.

3. Garcia C V, Paim C S, Martin S and Elfrides El-S S, J Pharm Biomed Anal., 2006, 41, 833-837.

4. El-Gindy A, El-Yazby F and Maher M M, J Pharm Biomed Anal., 2003, 31, 229-242.

5. $\quad$ Radi A, El-Ghany N A and Wahdan T, IL Farmaco. 2004, 59, 515-518.

6. Sabnis S S, Dhavale N D, Jadhav V Y and Gandhi S V, Spectrochimica Acta A, 2008, 69, 849-852.

7. Rao R N, Narasa Raju A and Nagaraju D, Talanta, 2006, 70(4), 805-810.

8. Shrinivas K S V, Buchireddy R, Mukkanti K and Srinivasulu P, Chromatographia, 2009, 69, 381-384.

9. Vora A, Damle M, Bhat L and Godge R, Chromatographia, 2007, 66, 941-943.

10. ICH Harmonised Tripartite Guideline: Validation of analytical procedures text and methodology 2005, Q2 (R1). 


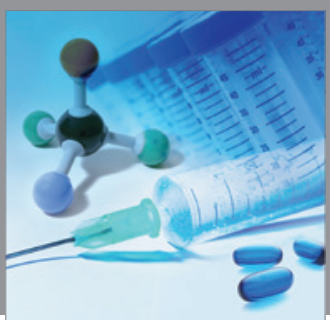

International Journal of

Medicinal Chemistry

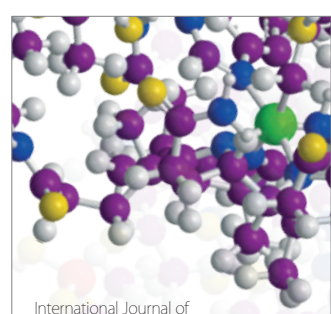

Carbohydrate Chemistry

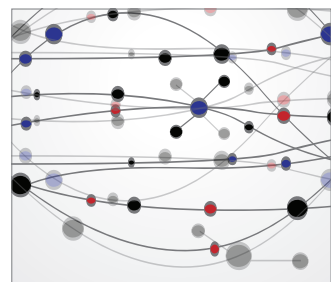

The Scientific World Journal
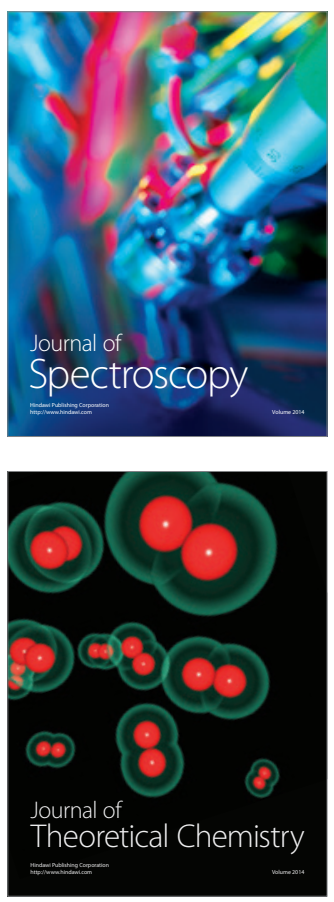
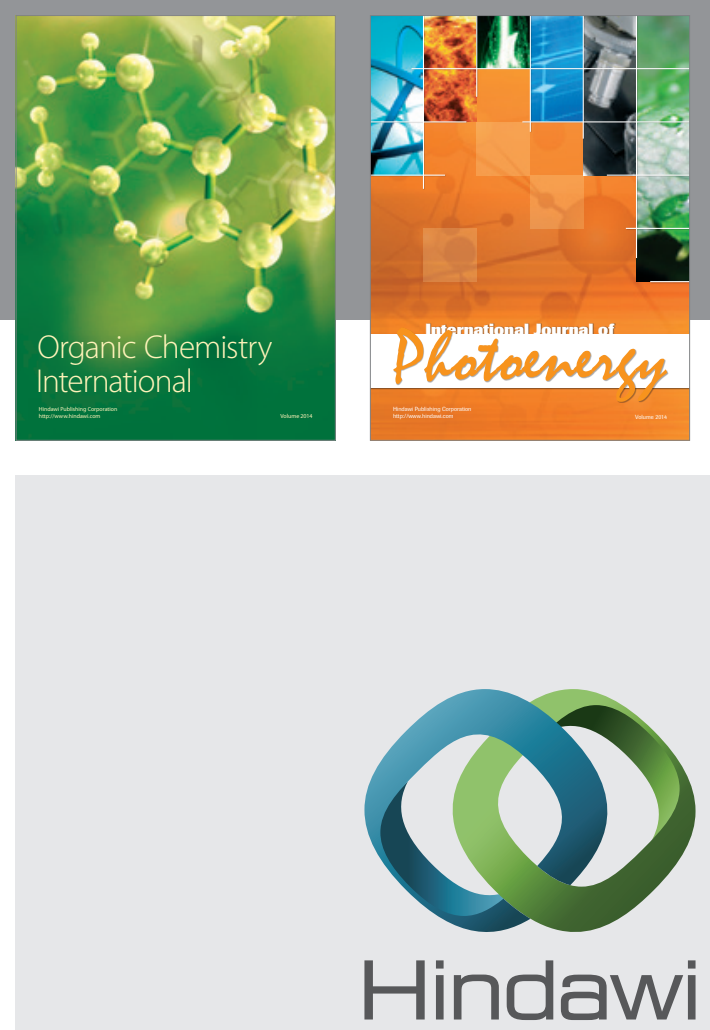

Submit your manuscripts at

http://www.hindawi.com
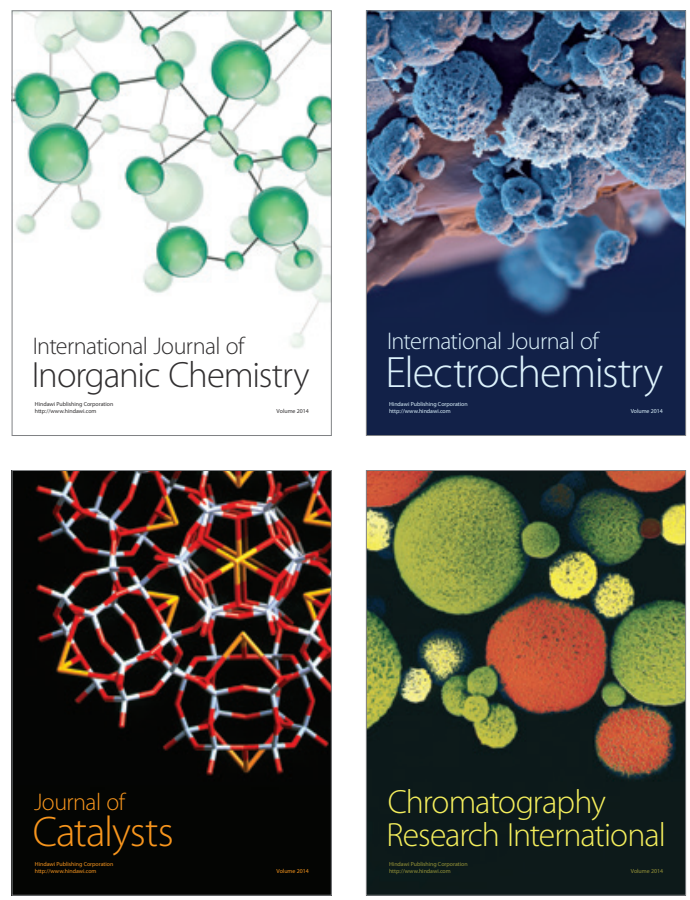
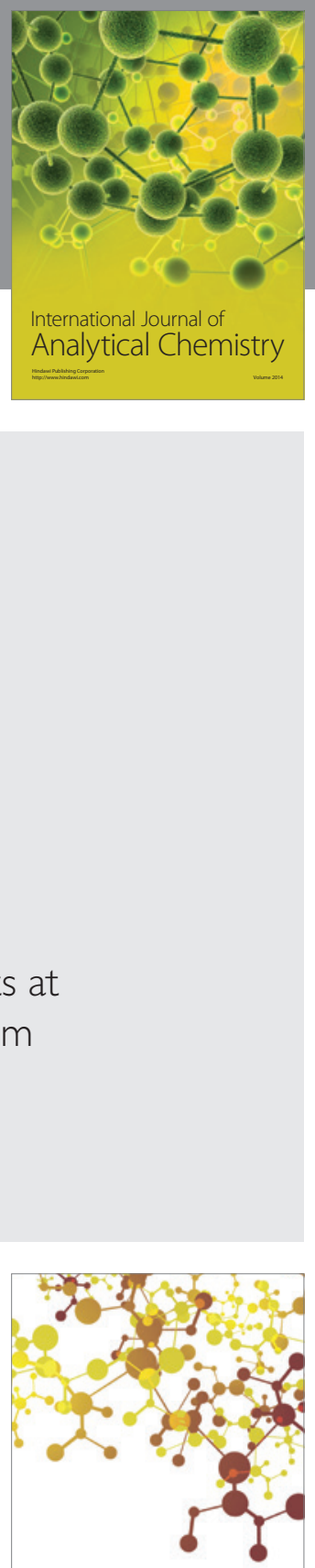

Journal of

Applied Chemistry
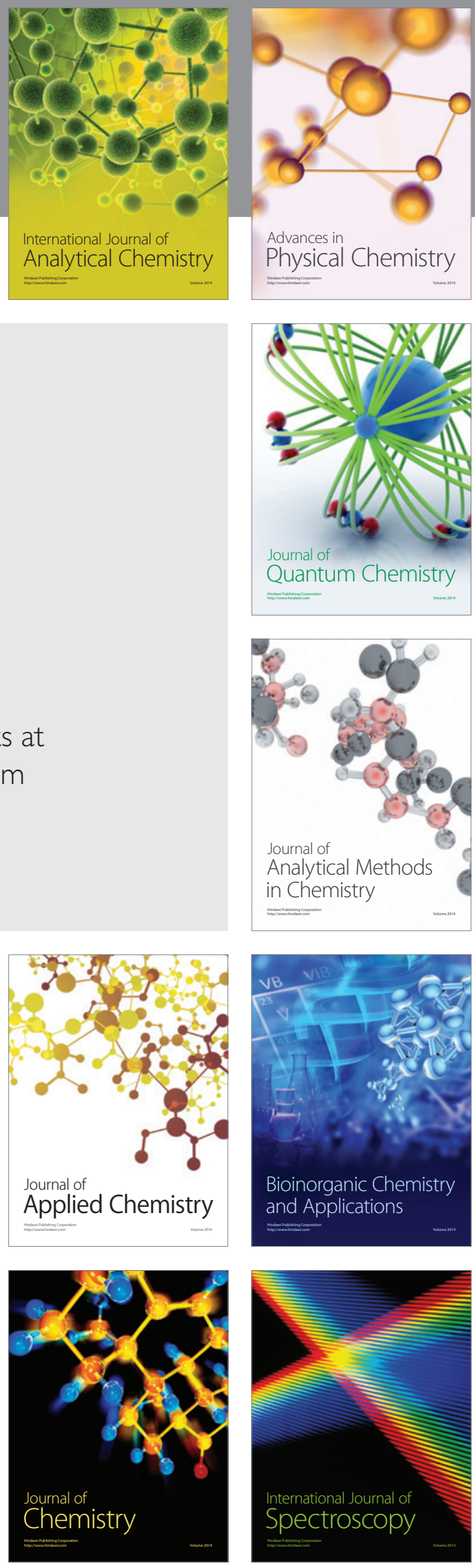